\title{
Determination and contents analysis of negative ions in vegetable simultaneous by ion chromatography
}

\author{
Yubai Zhang*, and Xuexi Tang \\ College of Marine Life Sciences, Ocean University of China, Qingdao, Shandong, 266000, China
}

\begin{abstract}
A method of high-speed to determine some negative ions and their contents in vegetable by ion chromatography is proposed in this paper, which was based on the research of 2 negative ions in 16 kinds of vegetable from Hainan Danzhou market. This method is of easy usage, high-speed, good reappearance and the result is satisfactory. The correlation coefficients $(r)$ of $\mathrm{NO}_{2}^{-}$and $\mathrm{NO}_{3}^{-}$were 0.9998 and 0.9991.Relative standard deviations $(R S D)$ were $0.65 \%$ and $0.04 \%$, respectively.By the determination of $\mathrm{NO}_{2}^{-}$, and $\mathrm{NO}_{3}^{-}$in vegetable, the results indicated that the contents of negative ions in different vegetables (the organ for eating) are fairly different.
\end{abstract}

\section{Introduction}

Negative ions content in vegetables are related to varieties, environment, and planting pattern. Anions content has become beyond the standard as well as an increased dependence on chemical fertilizers in modern agriculture. The over-standard of vegetable nitrate content is serious and nitrite content is also over-standard from time to time.[1, 2] In addition, it was reported that over $80 \%$ nitrate content in human body originated from the vegetables.[3, 4] In the human body, supernitrate can deoxidize nitrite by germ. Further, nitrite causes the animal toxicosis by producing methemoglobin even death. Nitrite indirectly combined with sub-amine also forms strong carcinogens-nitrous acid, which causes digestive system cancer.[5,6] Detection method of negative Ions content in vegetables has gradually attracted researcher attention.

Over the years, there are several analytical methods to determine inorganic anion, such as polarography, indirect complexometric titration, spectrophotometry, fluorescence, gas chromatography, and ion chromatography, some of which are complex and the corresponding experimental processes are not easy to be controlled. Nevertheless, ion chromatography has been mainly used for anionic determination and was widely applied in environmental and drug analysis.[7, 8] This method is characteristic of easy usage, highspeed, good reappearance and the satisfactory result has also been demonstrated.[9-11] Due to environmental pollution, especially accompanied with wide application of fertilizers and pesticides, the residual materials in plant, such as $\mathrm{NO}_{2}^{-}$and $\mathrm{NO}_{3}^{-}$, were paid more attention.

\footnotetext{
* Corresponding author: zhangyubai@shandong.cn
} 
In this present study, the anions contents in 16 kinds of vegetable collected in Danzhou Hainan market were investigated by ion chromatography. With the most convenient method and suitable ion chromatography conditions, $\mathrm{NO}_{2}{ }^{-}$, and $\mathrm{NO}_{3}{ }^{-}$contents in vegetable (the organ for eating) were simultaneously determined.

\section{Materials and methods}

\subsection{Materials}

For the representative research, the experimental materials were stochastically taken from market. 16 kinds of vegetable, including radish, carrot, potato, pachyrhizus leaf, swamp cabbage, greengrocery, Chinese cabbage, eggplant, tomato, green pepper, green cucumber, cuke, wax gourd, leek, scallion, bean sprout were selected. Every kind of the vegetable was chosen from 3 different stands was bought at per stand. From July $13^{\text {th }}$ to $14^{\text {th }}, 2019,48$ samples were obtained.

The fresh vegetables samples were washed with tap water, dried in the air, and further washed Milli-Q water 2-3 times and dried in the air, similarly. For the preparation, the sample was chopped with stainless steel knife and grounded into homogenate under $4^{\circ} \mathrm{C}$ with an agate ball mill. Then, the homogenate was stored at $4^{\circ} \mathrm{C}$.

\subsection{Apparatus and reagents}

\subsubsection{Apparatus}

Metrohm 761 Compact Ion Chromatography: Metrosep A supp 4-250 Ion Separator Column, Metrosep A Supp 4/5 Guard Column;

Millipore Milli-Q water $(18.2 \mathrm{M} \Omega \bullet \mathrm{cm})$;

$0.45 \mu \mathrm{m}$ Filtering apparatus;

\subsubsection{Chromatographic condition}

Ion separator column: 6.1006.430 Metrosep Anion Supp 4 (250mmL×4.0mmID);

Guard column: 6.1006.500 Metrosep A Supp 4/5 Guard;

Eluent: $1.7 \mathrm{mmol} / \mathrm{L} \mathrm{NaHCO}_{3}, 1.8 \mathrm{mmol} / \mathrm{L} \mathrm{Na}_{2} \mathrm{CO}_{3}$ mixed liquor, $1 \mathrm{~mL} / \mathrm{min}$ velocity;

Volume of sample: $20 \mu \mathrm{L}$;

Regenerator liquid: $50 \mathrm{mmol} / \mathrm{L} \mathrm{H}_{2} \mathrm{SO}_{4}$ solution;

Column temperature: $25^{\circ} \mathrm{C}$.

\subsubsection{Standard curve}

Analytic reagent $\mathrm{NaNO}_{3}(1.3708 \mathrm{~g})$ were dried at $105^{\circ}$ Cover 2 hours and cooled in a dryer for 30 minutes. Analytic reagent $\mathrm{NaNO}_{2}(1.4997 \mathrm{~g})$ were cooled in a dryer over 24 hours. The standard solution of $\mathrm{NO}_{3}{ }^{-}$and $\mathrm{NO}_{2}{ }^{-} 1000 \mathrm{mg} / \mathrm{L}$ was respectively prepared with the analytic reagents and then stored at $4^{\circ} \mathrm{C}$.

Each kind of the standard solution was diluted into inorganic anion standard solution with different low concentration of $1 \mathrm{mg} / \mathrm{L}, 10 \mathrm{mg} / \mathrm{L}, 20 \mathrm{mg} / \mathrm{L}, 50 \mathrm{mg} / \mathrm{L}$ and $100 \mathrm{mg} / \mathrm{L}$ in volumetric flask, respectively. In the chromatographic condition, every concentration was determined 5 times. The standard curve was drawn according to the ions concentration of the inorganic anion standard solution and the average value of the peak area and height. 


\subsection{Determine method}

\subsubsection{Sample solution}

Take $5 \mathrm{ml}$ vegetable homogenate and dilute to $25 \mathrm{ml}$ in a $25 \mathrm{ml}$-volumetric flask with Milli-Q water. Shake the solution well. After filtrating the solution with $0.45 \mu \mathrm{m}$ filtering apparatus, the filtrate was obtained as the sample solution.

\subsubsection{Negative lons determination}

Put $5 \mathrm{ml}$ sample solution into the ion chromatograph, record the test result according to the blank correction peak area. The Qualitative analysis was according to the retention time and the increased peak height. The Quantitative analysis was based on the standard curve. If the response peak value of sample solution exceeded the linearity range of the standard curve, the sample needed to be diluted with Milli-Q water, and then determined again.

\subsubsection{Quality control and assurance measures}

3 Blank samples were arranged in each batch (about 20 samples) of the sample solution to confirm the cleaning degree of the reagent and container. In every species, the standard solution recovery of each kind of vegetable sample solution was also analyzed, respectively. Additionally, three parallel samples were conducted in the experiment to confirm the reappearance of the result.

\section{Results and analysis}

\subsection{Sample mensurated result}

\subsubsection{Anion content in sample}

The contents ( 2 species of anions in 16 species of vegetables (the organ for eating)) were mensurated using forenamed 2.7 method.

Table 1. $\mathrm{NO}_{2}{ }^{-}$Contents in vegetables $\left(\mathrm{mg} \cdot \mathrm{NO}_{2}{ }^{-} / \mathrm{kg} \cdot\right.$ Fresh weight).

\begin{tabular}{llccc}
\hline \multicolumn{1}{c}{ Species } & \multicolumn{1}{c}{ Names } & Mean $\bar{X}$ & Ranges & C.V.(\%) \\
& Radish & 6.69 & $5.23 \sim 9.61$ & 30.93 \\
Root vegetables & Carrot & 14.21 & $13.77 \sim 14.67$ & 2.60 \\
& Potato & 27.86 & $21.70 \sim 33.68$ & 43.34 \\
\hline \multirow{3}{*}{ Leaf vegetables } & Pachyrhizus leaf & 14.45 & $13.29 \sim 15.72$ & 6.90 \\
& Swamp Cabbage & & & 0.00 \\
& Greengrocery & 10.68 & $8.71 \sim 14.08$ & 22.65 \\
& Chinese cabbage & 5.12 & $4.27 \sim 5.76$ & 12.19 \\
\hline \multirow{2}{*}{ Selanageous fruits } & Eggplant & 10.00 & $9.72 \sim 10.36$ & 2.65 \\
& Tomato & 4.87 & $0.00 \sim 8.05$ & 71.80 \\
& Green pepper & 12.23 & $6.08 \sim 20.57$ & 50.02 \\
\hline \multirow{2}{*}{ Cucurbits crops } & Green cucumber & 3.93 & $0.00 \sim 6.67$ & 72.54 \\
& Cuke & 7.45 & $4.39 \sim 12.73$ & 50.21 \\
\hline \multirow{2}{*}{ Bulb crops } & Wax gourd & 5.27 & $4.41 \sim 6.43$ & 16.18 \\
\hline Beans & Leek & 5.15 & $0.00 \sim 15.44$ & 141.42 \\
\hline Note: & Scallion & 12.71 & $11.54 \sim 13.59$ & 6.78 \\
\hline
\end{tabular}

Note: - Not detected; 
Table 2. $\mathrm{NO}_{3}{ }^{-}$Contents in vegetables $\left(\mathrm{mg} \bullet \mathrm{NO}_{3}{ }^{-} / \mathrm{kg} \cdot\right.$ Fresh weight $)$.

\begin{tabular}{llccc}
\hline \multicolumn{1}{c}{ Species } & \multicolumn{1}{c}{ Names } & Mean $\bar{X}$ & Ranges & C.V. (\%) \\
\hline \multirow{4}{*}{ Root vegetables } & Radish & 1618.45 & $1028.20 \sim 2250.29$ & 37.82 \\
& Carrot & 157.75 & $99.46 \sim 236.27$ & 44.76 \\
& Potato & 185.39 & $83.91 \sim 359.92$ & 81.45 \\
\hline \multirow{4}{*}{ Leaf vegetables } & Pachyrhizus leaf & 1552.53 & $1279.48 \sim 1980.39$ & 24.17 \\
& Swamp Cabbage & 932.50 & $198.67 \sim 2277.62$ & 125.10 \\
& Greengrocery & 4011.10 & $3064.65 \sim 5049.96$ & 24.83 \\
& Chinese cabbage & 1582.04 & $738.37 \sim 2359.30$ & 51.36 \\
\hline \multirow{4}{*}{ Selanageous fruits } & Eggplant & 317.19 & $272.30 \sim 357.15$ & 13.44 \\
& Tomato & 63.19 & $60.61 \sim 67.34$ & 5.73 \\
& Green pepper & 64.90 & $40.02 \sim 100.08$ & 48.27 \\
\hline \multirow{2}{*}{ Cucurbits crops } & Green cucumber & 56.86 & $22.70 \sim 75.24$ & 52.08 \\
& Cuke & 166.60 & $83.68 \sim 215.67$ & 43.34 \\
& Wax gourd & 364.64 & $344.17 \sim 403.78$ & 9.30 \\
\hline \multirow{2}{*}{ Bulb crops } & Leek & 1114.16 & $985.26 \sim 1214.08$ & 10.51 \\
& Scallion & 366.75 & $284.39 \sim 472.25$ & 26.19 \\
\hline Beans & Bean sprout & 57.50 & $46.48 \sim 71.93$ & 22.72 \\
\hline
\end{tabular}

\subsubsection{Linear correlation}

The regression equation correlation coefficient of $\mathrm{NO}_{2}{ }^{-}$, and $\mathrm{NO}_{3}{ }^{-}$are shown in table 3 , and it can be concluded, the concentrations of all the 2 species negative ions exhibit good linear correlation.

Table 3. Linear range and regression equation of 2 negative ions.

\begin{tabular}{cccc}
\hline Ions & Regression equation & Correlation coefficient $(r)$ & $R S D(\%)$ \\
\hline $\mathrm{NO}_{2}{ }^{-}$ & $\mathrm{Y}=3.09604 \mathrm{x}+25.1962$ & 0.9998 & 2.507 \\
$\mathrm{NO}_{3}{ }^{-}$ & $\mathrm{Y}=3.62298 \mathrm{x}+48.0246$ & 0.9991 & 5.466 \\
\hline
\end{tabular}

\subsubsection{Precision test}

In general, precision test reflect the stability of the method utilized. Under the same chromatographic condition, the standard solution of $50 \mathrm{mg} / \mathrm{L} \mathrm{NO}_{2}{ }^{-}$, and $\mathrm{NO}_{3}{ }^{-}$were carried out 3 times continuously, and then the relative standard deviation $(R S D)$ was separately achieved. As followed in table 4, it can be concluded that the precision of the test method is good.

Table 4. Relative standard deviation $(R S D)$ of 2 negative ions.

\begin{tabular}{ccc}
\hline Ions & $\mathrm{NO}_{2}^{-}$ & $\mathrm{NO}_{3}{ }^{-}$ \\
\hline$R S D(\%)$ & 0.65 & 0.04 \\
\hline
\end{tabular}

\subsubsection{Recovery test}

It is known that high and low level of recovery correlate with the accuracy and reliability of ion chromatographic method when testing negative ions. The main influencing factors consist of ultrapure water, leacheate flow, and environment temperature and operation technology. Using eggplant, swamp cabbage and pachyrhizus leaf as sample background, the recovery rates of vegetables were tested, respectively. After weighing the sample 
accurately and processing upon the 2.7 method, the mixed standard solution was added. By using the standard addition method parallel to determination of $\mathrm{NO}_{2}^{-}$, and $\mathrm{NO}_{3}{ }^{-}$content in three samples of vegetables the recovery rate of this method was calculated, respectively. As shown from the results (table 5), the recovery of 2 species negative ions in vegetables are high. The obtained analytical results are accurate.

Table 5. Results of recovery test.

\begin{tabular}{ccc}
\hline \multicolumn{3}{c}{ Average Recovery(\%) } \\
\hline Item & $\mathrm{NO}_{2}{ }^{-}$ & $\mathrm{NO}_{3}{ }^{-}$ \\
\hline Vegetables & 106.2 & 94.9 \\
\hline
\end{tabular}

\subsection{Content analysis}

The contents of 2 species negative ions $\left(\mathrm{mg} \cdot \mathrm{Cl}^{-} / \mathrm{kg} \cdot\right.$ fresh weight, the same below) are very different in various species and fruits. By combining table 1 to table 2 and table 6 , it can be concluded that the contents of $\mathrm{NO}_{3}{ }^{-}$ions in leaf vegetables and bulb crops are higher than them in beans, cucurbits crops, selanageous fruits vegetables etc. It suggests that leaf vegetables and bulb crops absorb and accumulate $\mathrm{NO}_{3}{ }^{-}$ions more easily, which is consistent with the predecessor research results.[12-14] Differences in the mean content of nitrite ions in different categories of vegetables are not significant, but vary widely in different species of vegetables. It may be related to its low stability, making it easily to change into $\mathrm{NO}_{3}^{-}$ions etc.

Table 6. $\mathrm{NO}_{2}{ }^{-}$, and $\mathrm{NO}_{3}{ }^{-}$average contents $\left(\mathrm{mg} \cdot \mathrm{Cl}^{-} / \mathrm{kg} \bullet\right.$ fresh weight).

\begin{tabular}{ccccccc}
\hline Ions & $\begin{array}{c}\text { Root } \\
\text { vegetables }\end{array}$ & $\begin{array}{c}\text { Leaf } \\
\text { vegetables }\end{array}$ & $\begin{array}{c}\text { Selanageous } \\
\text { fruits }\end{array}$ & $\begin{array}{c}\text { Cucurbits } \\
\text { crops }\end{array}$ & $\begin{array}{c}\text { Bulb } \\
\text { crops }\end{array}$ & Beans \\
\hline $\mathrm{NO}_{2}{ }^{-}$ & 16.25 & 7.56 & 9.03 & 5.55 & 8.93 & 11.29 \\
$\mathrm{NO}_{3}{ }^{-}$ & 653.86 & 2019.54 & 148.43 & 196.03 & 740.46 & 57.5 \\
\hline
\end{tabular}

It can be concluded that the variation coefficient of most of the four kinds of anion content in vegetables is medium variability $(C . V .=10 \% \sim 100 \%)$ from table 1 to table 2 different vegetables of all kinds of anion content, individual vegetable high or low. This shows that among all kinds of man-made or natural factors, the variation coefficient of the 2 kinds of anion content in vegetables is the largest.

It suggests that the 2 negative ions content may possibly be associated with the variety difference, different farming and planting way, environment condition, fertilizer difference and microorganism degradation, picking time and others. Relatively speaking, the contents of these 2 kinds of negative ions in vegetables with small variation coefficient are stable. They are not easily influenced by the varieties and environment conditions, and so on.

\section{Conclusion}

The obtained results show that this method, which uses ion chromatography to test 2 species of anion in vegetables is simple, rapid, and reproducible. The correlation coefficients $(r)$ of $\mathrm{NO}_{2}{ }^{-}$and $\mathrm{NO}_{3}{ }^{-}$were 0.9998 and 0.9991 . Relative standard deviations $(R S D)$ were $0.65 \%$ and $0.04 \%$, respectively. It can test 2 species of vegetables negative ion $\mathrm{NO}_{2}{ }^{-}$ and $\mathrm{NO}_{3}{ }^{-}$at the same time. Nevertheless, it was found that the determination results of ions $\mathrm{F}^{-}$in vegetables and $\mathrm{F}^{-}, \mathrm{NO}_{2}^{-}$and $\mathrm{NO}_{3}^{-}$in fruits are not satisfactory. The recovery rate is low or high, and whether this method is appropriate for testing the vegetables, which didn't involve in this test, need be studied further in the subsequent tests. In this present study, filtering samples with $0.45 \mu \mathrm{m}$ filter membrane during pretreatment has a good removal effect for organic compounds in vegetables, such as pigments and lipids. Additionally, the 
best way is to use $\mathrm{C}_{18}$ column or pretreatment column filled PVP, which is more ideal for the chromatography column protection. [15]

The species and amount of anion content in fruits and vegetables vary widely in the experiment. It may be associated with the species and genetic characteristics of fruits and vegetables. In addition, farmers chase productivity through the use of large quantities fertilizer and pesticides. This is also one of the causes of the displayed differences. Hainan province is an important producing area for Chinese anti-season vegetables and fruits. It is important to establish and improve a set of technology system for keeping the high yield and high-quality of tropical fruits and vegetables, especially in strengthening the study of rational fertilization and preventing plant diseases and insect pests to reduce the health impact of negative ion content in fruit and vegetables.

\section{References}

1. Qu Y. X., Luo G. J.. Xiandai Horticulture, (3) :16(2019).

2. Zhang J. D.. Journal of Xi'an University(Natural Science Edition).(1)65(2021).

3. Ye W. Q. . Modern Food,(24) :191(2020).

4. Wang W. J. . China Food Safety Magazine,(36): 119(2020).

5. Leng T. ., Journal of Food Safety \& Quality, (19):6970(2020).

6. Wang H. Y., Anhui Chemical Industry, (3) :116(2020)

7. Ding Y., Mou S.. Chinese journal of chromatography, 20(3): 262 264(2002).

8. Song Z. R. . China Inspection Body \& Laboratory, (6): 14. (2019)

9. Mou S., Liu K.. Application of ion chromatography [M].Beijing :Chemical industry press, 24 26(2000).

10. Deng L. L. . Modern Food, (21): 191. (2019)

11. Zhang J., Zhou J., Wu Z.. PTCA (PART B: chemical analysis), 38(1): 29(2002).

12. Zhou Y. W. . Guangzhou Chemical Industry, (20): 29(2019).

13. Huang J., Yuan L.. Acta Ecologica Sinica, 16(4): 383 388(1996).

14. Wang L., Xiang C., Wang Y.. Hubei Agricultural Sciences, (3): 71 72(2003).

15. Siu D C, Henshall A, Dasgupta P K. Journal of Chromatography A, 804(1-2): 157 160(1998). 